\title{
Clinical effect of postoperative chemoradiotherapy in resected advanced laryngeal squamous cell carcinoma
}

\author{
MING ZHANG $^{1 *}$, WEIYE DENG $^{2 *}$, HONGLI GONG ${ }^{1}$, CAI LI $^{1}$, YIFAN WANG $^{2}$, \\ XIANGYU LIU ${ }^{3}$, LEITAO ${ }^{1}$ and LIANG ZHOU ${ }^{1}$ \\ ${ }^{1}$ Department of Otorhinolaryngology-Head and Neck Surgery, Eye, Ear, Nose and Throat Hospital of Fudan University, \\ Shanghai 200031, P.R. China; ${ }^{2}$ Departments of Radiation Oncology, The University of Texas Southwestern \\ Medical Center, Dallas, TX 75390; ${ }^{3}$ Department of Biostatistics and Data Science, School of Public Health, \\ The University of Texas Health Science Center at Houston, Houston, TX 77030, USA
}

Received January 27, 2018; Accepted January 25, 2019

DOI: $10.3892 /$ ol.2019.10104

\begin{abstract}
Laryngeal squamous cell carcinoma (LSCC) is one of the most prevalent types of head and neck malignancies. Advanced LSCC has failed to demonstrate a satisfactory prognosis, despite the progresses in the diagnosis and treatment, and the optimal treatment modality continues to be debated. To evaluate the clinical utility and survival outcomes of adjuvant chemoradiotherapy (CRT) for patients with resected advanced LSCC, a retrospective analysis of 232 patients with LSCC who had undergone total laryngectomy and neck dissection between 2005 and 2010 was conducted. Of the 232 eligible patients, 167 patients $(72 \%)$ received surgery alone, whereas 65 patients $(28 \%)$ received surgery + adjuvant CRT. In the overall cohort, the 5- and 10-year overall survival (OS) rates were 55.2 and $48.3 \%$, respectively. Multivariate analysis revealed that the clinical stage was significantly associated with OS. However, the $\mathrm{N}$ classification was an independent indicator in disease-free survival and laryngeal cancer-specific survival. In those patients with stage IV disease, patients receiving adjuvant CRT exhibited a markedly improved survival benefit compared with patients receiving surgical treatment only, following propensity score matching of the data $(\mathrm{P}<0.05)$. The application of adjuvant CRT confers additional survival benefits in comparison with surgery-only treatment regimens for advanced LSCC. However, additional prospective studies are required.
\end{abstract}

Correspondence to: Dr Liang Zhou, Department of Otorhinolaryngology-Head and Neck Surgery, Eye, Ear, Nose and Throat Hospital of Fudan University, 83 Fenyang Road, Shanghai 200031, P.R. China

E-mail: zhoulent@126.com

${ }^{*}$ Contributed equally

Key words: laryngeal cancer, squamous cell carcinoma, chemoradiotherapy, survival, prognosis

\section{Introduction}

Laryngeal squamous cell carcinoma (LSCC) is one of the most prevalent types of head and neck malignancies, and it has an estimated incidence of 5.1-10 cases per 100,000 worldwide (1). The majority of patients $(\sim 60 \%)$ present with stage III or stage IV disease at diagnosis (2). LSCC has been one of the few cancer types with a decreased survival outcome over the past 40 years in the United States of America $(2,3)$. Due to the large population, China has reported $\sim 13.0 \%$ of laryngeal cancer (LC) cases and $14.7 \%$ of LC-specific mortalities within the global LC population (4).

The treatment modalities for LSCC include surgery, chemotherapy, radiotherapy or the combination of these therapies $(1,5)$. Adjuvant chemoradiotherapy (CRT) is recommended for resected locally advanced head and neck cancer with positive surgical margins or extracapsular extension, according to 2 randomized clinical trials: The Intergroup Radiation Therapy Oncology Group (RTOG) 95-01 and European Organization for Research and Treatment of Cancer 22931 (6-8). Advanced LSCC has failed to demonstrate a satisfactory prognosis despite the progress in the diagnosis and treatment of LSCC, and the optimal treatment modality continues to be debated (9-11).

Previous study on the treatment of LSCC has focused on the comparison between primary radiotherapy and CRT (12), and there have been few studies performed to compare surgery and surgery + adjuvant CRT for patients with advanced LSCC. The aim of the present study was to determine the clinical effect of adjuvant CRT for patients with advanced LSCC who underwent initial surgeries in a single institution over a 10 -year post-treatment follow-up.

\section{Materials and methods}

Patient selection. The medical records of patients with previously untreated LSCC were retrospectively reviewed. The patients were recruited between January 2005 and December 2010 from the Department of Otorhinolaryngology-Head and Neck Surgery, Eye, Ear, Nose and Throat Hospital of the Fudan University (Shanghai, China). The total number 
of patients with complete medical records during the time interval was 235. The diagnosis and treatment of all patients with LSCC were based on collaboration within a multidisciplinary medical team. Data regarding patient demographics, tumor characteristics and treatment modalities were obtained by reviewing medical records. Approval from the Institutional Review Board of the Eye, Ear, Nose and Throat Hospital of Fudan University (Shanghai, China) was obtained for the present study. All patients gave their full consent to participate in the present study, and a written consent form was obtained from each patient.

Treatment and follow-up. All the patients were initially treated with total laryngectomy and neck dissection. The type of neck dissection depended on the particular clinical situation. Adjuvant CRT was primarily performed in cases of $\mathrm{pN} 2+$ stage disease (according to the AJCC TNM staging system, 7th edition) or in cases of positive surgical margins and/or extracapsular spread in the pathological examination (13). Physical examination and computerized tomography were performed for regular follow-up if required. For the first 2 years, follow-up was performed every 1-3 months. Subsequently, it was performed every 4-6 months for the third year. Following that, the follow-ups continued annually until the end of the study period. No patients were lost to follow-up.

Statistical analysis. Descriptive statistics were compiled to characterize the patients receiving surgery vs. surgery + adjuvant CRT. The differences between these two groups were evaluated using a $\chi^{2}$ test or Fisher's exact test for categorical variables. Time-to-event was measured from the date of initial surgical resection. Outcome measures were laryngeal cancer-specific survival (CSS), overall survival (OS) and disease-free survival (DFS). Patients were censored at the time of their last follow-up. Survival times were calculated from the day of surgery to the date of occurrence of an event or from the date of the last follow-up. Survival outcomes were calculated using the Kaplan-Meier method. The differences between survival curves were analyzed using a log-rank test. Univariate and multivariate analyses of survival outcomes were accomplished using Cox proportional hazards modeling. Variables with $\mathrm{P}<0.05$ in the univariate analysis were entered into the multivariate analysis to determine independent indicators of treatment outcome. Propensity-score matching (PSM) was then performed to decrease the effects of potential confounding factors: One-to-one propensity matching without replacement was completed using the nearest-neighbor matching algorithm (14,15). Analyses were performed using the SPSS v24.0 statistical software package (IBM Corporation, Armonk, NY, USA) and Stata 14.0 (StataCorp LP, College Station, TX, USA). All statistics were double-sided, and $\mathrm{P}<0.05$ was considered to indicate a statistically significant difference.

\section{Results}

Patient characteristics. A total of 232 patients with LSCC [230 males (99.2\%) and 2 females (0.8\%)] were included in the present study (Table I). The median age was 61.0 years (range, 36-82 years) and 59.1\% (137 patients) were $\geq 60$ years of age. At diagnosis, 83 patients $(35.8 \%)$ were diagnosed with stage III disease, while 149 patients $(64.2 \%)$ were diagnosed with stage IV disease. N classification included N0 ( $\mathrm{n}=45$; $19.4 \%), \mathrm{N} 1(\mathrm{n}=61 ; 26.3 \%), \mathrm{N} 2(\mathrm{n}=108 ; 46.6 \%)$ and N3 $(\mathrm{n}=18$; $7.8 \%$ ). In total, 167 patients received surgery, and 65 patients received surgery + adjuvant CRT. An increased number of patients with $\mathrm{N}+$ disease received adjuvant CRT compared with those patients with N0 disease (31.0 vs. 18.4\%). Of all the 232 patients, 25 patients exhibited positive surgical margins and/or extracapsular spread, and they were all in the surgical + adjuvant CRT group.

Survival analysis. The median follow-up for all patients was 46.8 months (range, 4.9-140.8 months). Of the 232 patients, 114 patients $(49.1 \%)$ succumbed to LSCC and 6 patients $(2.6 \%)$ succumbed as a result of other causes. Cumulatively, the 3/5-year OS, DFS and CSS rates were 69.4/55.2, 58.6/47.4 and $69.4 / 56.5 \%$, respectively. Prognostic factors for a poorer OS identified in the univariate analysis were age ( $<60$ vs. $\geq 60$ years; $\mathrm{P}=0.045$ ), $\mathrm{N}$ classification ( $\mathrm{N} 0$ vs. $\mathrm{N}+$; $\mathrm{P}=0.006$ ) and clinical stage (III vs. IV; $\mathrm{P}=0.004)$. N classification and stage were also statistically significant factors in DFS and CSS according to univariate analysis $(\mathrm{P}<0.05$; Table II). No differences regarding primary tumor localization, $\mathrm{T}$ classification, smoking and alcohol consumption history were demonstrated for these 3 endpoints. Multivariate analysis revealed that age ( $<60$ vs. $\geq 60$ years; $P=0.035)$ and stage (III vs. IV; $\mathrm{P}=0.022$ ) were statistically significant factors in $\mathrm{OS}$, whereas $\mathrm{N}$ classification ( $\mathrm{N} 0$ vs. $\mathrm{N}+$ ) was the independent factor in DFS $(\mathrm{P}=0.015)$ and CSS $(\mathrm{P}=0.043)$ (Table III).

Comparison of treatment modalities prior to and following $P S M$. As the $\mathrm{N}$ classification and clinical stage were the significant indicators from the survival analysis and they were not well balanced for the surgery and surgery + CRT groups, PSM was additionally performed to obtain a matched cohort and to investigate if there were any survival differences between the two groups (16-18). The patient characteristics following matching with well-balanced $\mathrm{N}$ classification and stage are summarized in Table IV. Prior to PSM, there was no statistical significance between the two treatment groups by log-rank tests, but it appeared that the surgery-only group may have exhibited improved survival outcomes compared with the surgery + CRT group in OS and CSS (Fig. 1). Following PSM, it was revealed that patients who underwent surgery + CRT exhibited an improved survival outcome compared with patients who only underwent surgery (Fig. 2). Following stratification by stage, patients at stage IV continued to exhibit an improved survival benefit in the surgery + CRT group compared with the surgery-only group for all 3 endpoints. No significant difference in OS or CSS was observed in patients with stage III disease (Fig. 3). For patients with pN2 disease, no statistical significance was observed between the two groups. Following matching the $\mathrm{T}$ stage, patients with pN2 stage LC exhibited an improved survival benefit in the surgery + CRT group compared with the surgery-only group (Fig. 4).

\section{Discussion}

Previously, the primary approach to therapy for advanced LSCC was surgical treatment $(19,20)$. At present, multiple 
Table I. Baseline patient characteristics in the 232 unmatched patients with resected laryngeal cancer who had undergone surgery alone or surgery with adjuvant CRT.

\begin{tabular}{|c|c|c|c|c|}
\hline \multirow[b]{2}{*}{ Variable } & \multicolumn{3}{|c|}{ Treatment groups, no. of patients $(\%)$} & \multirow[b]{2}{*}{ P-value } \\
\hline & Total & Surgery & Surgery + CRT & \\
\hline Age, years & & & & 0.681 \\
\hline$<60$ & $95(40.9)$ & $67(40.1)$ & $28(43.1)$ & \\
\hline$\geq 60$ & $137(59.1)$ & $100(59.9)$ & $37(56.9)$ & \\
\hline Sex & & & & 1.000 \\
\hline Male & $230(99.1)$ & $165(98.8)$ & $65(100.0)$ & \\
\hline Female & $2(0.9)$ & $2(1.2)$ & $0(0.0)$ & \\
\hline Smoking history & & & & 0.385 \\
\hline Yes & $188(81.0)$ & 133 (79.6) & $55(84.6)$ & \\
\hline No & $44(19.0)$ & $34(20.4)$ & $10(15.4)$ & \\
\hline Alcohol consumption & & & & 0.508 \\
\hline Yes & $124(53.4)$ & $87(52.1)$ & $37(56.9)$ & \\
\hline No & $108(46.6)$ & $80(47.9)$ & $28(43.1)$ & \\
\hline Primary tumor site & & & & 0.473 \\
\hline Supraglottis & $161(69.4)$ & $112(67.1)$ & $49(75.4)$ & \\
\hline Glottis & $70(30.2)$ & $54(32.3)$ & $16(24.6)$ & \\
\hline Subglottis & $1(0.4)$ & $1(0.6)$ & $0(0.0)$ & \\
\hline $\mathrm{T}$ classification & & & & 0.771 \\
\hline $\mathrm{T} 1-\mathrm{T} 2$ & $42(18.1)$ & $31(18.6)$ & $11(16.9)$ & \\
\hline T3-T4 & $190(81.9)$ & $136(81.4)$ & $54(83.1)$ & \\
\hline $\mathrm{N}$ classification & & & & 0.038 \\
\hline N0 & $45(19.4)$ & $38(22.8)$ & $7(10.8)$ & \\
\hline $\mathrm{N}^{+}$ & $187(80.6)$ & $129(77.2)$ & $58(89.2)$ & \\
\hline Clinical Stage & & & & 0.005 \\
\hline III & $83(35.8)$ & $69(41.3)$ & $14(21.5)$ & \\
\hline IV & $149(64.2)$ & $98(58.7)$ & $51(78.5)$ & \\
\hline
\end{tabular}

CRT, adjuvant chemotherapy.

Table II. Univariate analysis of survival in 232 unmatched patients with laryngeal cancer.

\begin{tabular}{|c|c|c|c|c|c|c|}
\hline \multirow[b]{2}{*}{ Variables } & \multicolumn{2}{|c|}{ Overall survival } & \multicolumn{2}{|c|}{ Disease-free survival } & \multicolumn{2}{|c|}{ Cancer-specific survival } \\
\hline & HR $(95 \% \mathrm{CI})$ & P-value & HR $(95 \% \mathrm{CI})$ & $\mathrm{P}$-value & HR $(95 \% \mathrm{CI})$ & P-value \\
\hline Age $(<60$ vs. $\geq 60)$ & $1.47(1.01-2.14)$ & 0.045 & $1.06(0.75-1.50)$ & 0.740 & $1.42(0.97-2.08)$ & 0.073 \\
\hline Smoking history (yes vs. no) & $0.87(0.54-1.40)$ & 0.568 & $0.79(0.50-1.23)$ & 0.294 & $0.82(0.50-1.34)$ & 0.423 \\
\hline Alcohol consumption (yes vs. no) & $1.04(0.73-1.50)$ & 0.835 & $1.10(0.78-1.54)$ & 0.593 & $0.99(0.69-1.43)$ & 0.953 \\
\hline Primary site (supraglottis vs. glottis) & $1.02(0.69-1.51)$ & 0.925 & $0.96(0.67-1.40)$ & 0.841 & $1.08(0.73-1.61)$ & 0.705 \\
\hline T classification (T1-2 vs. T3-4) & $1.09(0.68-1.76)$ & 0.722 & $1.23(0.77-1.96)$ & 0.383 & $1.05(0.64-1.72)$ & 0.845 \\
\hline $\mathrm{N}$ classification (N0 vs. $\mathrm{N}^{+}$) & $2.10(1.24-3.57)$ & 0.006 & $2.05(1.26-3.34)$ & 0.004 & $2.11(1.22-3.64)$ & 0.007 \\
\hline Clinical Stage (III vs. IV) & $1.80(1.21-2.67)$ & 0.004 & $1.48(1.03-2.13)$ & 0.036 & $1.74(1.17-2.61)$ & 0.007 \\
\hline Treatment (Surgery vs. Surgery + CRT) & $1.40(0.96-2.05)$ & 0.083 & $1.06(0.73-1.53)$ & 0.776 & $1.33(0.90-1.97)$ & 0.152 \\
\hline
\end{tabular}

CRT, adjuvant chemotherapy; HR, hazard ratio; CI, confidence interval.

treatment modalities, including radiotherapy and chemoradiotherapy, have been introduced to treat advanced LSCC.
These were based on published clinical trials that revealed that increased rates of larynx preservation may be obtained 
Table III. Multivariate analysis of survival in 232 unmatched patients with laryngeal cancer.

\begin{tabular}{|c|c|c|c|c|c|c|}
\hline \multirow[b]{2}{*}{ Variable } & \multicolumn{2}{|c|}{ Overall survival } & \multicolumn{2}{|c|}{ Disease-free survival } & \multicolumn{2}{|c|}{ Cancer-specific survival } \\
\hline & $\operatorname{HR}(95 \% \mathrm{CI})$ & P-value & HR $(95 \%$ CI) & P-value & $\operatorname{HR}(95 \% \mathrm{CI})$ & P-value \\
\hline Age $(<60$ vs. $\geq 60)$ & $1.50(1.03-2.19)$ & 0.035 & - & - & - & - \\
\hline $\mathrm{N}$ classification ( $\mathrm{N} 0$ vs. $\mathrm{N}+$ ) & $1.70(0.98-2.96)$ & 0.059 & $1.88(1.13-3.13)$ & 0.015 & $1.80(1.02-3.17)$ & 0.043 \\
\hline Stage (III vs. IV) & $1.62(1.07-2.46)$ & 0.022 & $1.25(0.85-1.83)$ & 0.261 & $1.50(0.99-2.29)$ & 0.058 \\
\hline
\end{tabular}

Table IV. Baseline patient characteristics in the 130 propensity score-matched patients with resected laryngeal cancer who had undergone surgery alone or surgery with adjuvant CRT.

\begin{tabular}{|c|c|c|c|c|c|}
\hline \multirow[b]{2}{*}{ Variable } & \multicolumn{3}{|c|}{ Treatment groups, no. of patients $(\%)$} & \multirow[b]{2}{*}{ Standardized differences } & \multirow[b]{2}{*}{ P-value } \\
\hline & Total & Surgery & Surgery + CRT & & \\
\hline Age, y & & & & & 0.681 \\
\hline$<60$ & $56(43.1)$ & $28(43.1)$ & $28(43.1)$ & 0.000 & \\
\hline$\geq 60$ & $74(56.9)$ & $37(56.9)$ & $37(56.9)$ & & \\
\hline Sex & & & & & 1.000 \\
\hline Male & $129(99.2)$ & $64(98.5)$ & $65(100.0)$ & 0.175 & \\
\hline Female & $1(0.8)$ & $1(1.5)$ & $0(0.00)$ & & \\
\hline Smoking history & & & & & 0.385 \\
\hline Yes & $111(85.4)$ & $56(86.2)$ & $55(84.6)$ & -0.043 & \\
\hline No & $19(14.6)$ & $9(13.8)$ & $10(15.4)$ & & \\
\hline Alcohol consumption & & & & & 0.508 \\
\hline Yes & $71(54.6)$ & $34(52.3)$ & $37(56.9)$ & 0.092 & \\
\hline No & $59(45.4)$ & $31(47.7)$ & $28(43.1)$ & & \\
\hline Primary site & & & & & 0.473 \\
\hline Supraglottis & $92(70.8)$ & $43(66.2)$ & $49(75.4)$ & 0.202 & \\
\hline Glottis & $38(29.2)$ & $22(33.8)$ & $16(24.6)$ & & \\
\hline $\mathrm{T}$ classification & & & & & 0.771 \\
\hline $\mathrm{T} 1-\mathrm{T} 2$ & $21(16.2)$ & $10(15.4)$ & $11(16.9)$ & 0.041 & \\
\hline $\mathrm{T} 3-\mathrm{T} 4$ & $109(83.8)$ & $55(84.6)$ & $54(83.1)$ & & \\
\hline $\mathrm{N}$ classification & & & & & 0.038 \\
\hline N0 & $14(10.8)$ & $7(10.8)$ & $7(10.8)$ & 0.000 & \\
\hline $\mathrm{N}+$ & $116(89.2)$ & $58(89.2)$ & $58(89.2)$ & & \\
\hline Clinical Stage & & & & & 0.005 \\
\hline III & $28(21.5)$ & $14(21.5)$ & $14(21.5)$ & 0.000 & \\
\hline IV & $102(78.5)$ & $51(78.5)$ & $51(78.5)$ & & \\
\hline
\end{tabular}

CRT, adjuvant chemotherapy.

with chemoradiotherapy for advanced LC $(21,22)$. However, different treatment modalities or combinations have varied in different developing and developed countries (23).

Several clinical trials have been conducted to investigate the optimal treatment for LC $(21,24,25)$. The Veterans Administration randomized clinical trial (RCT) comprising two treatment arms revealed that the usage of primary CRT offered patients who underwent surgery an equal survival chance (17). Concomitantly, the CRT group had a two-thirds likelihood of preservation of the larynx for stage III/IV laryngeal cancer (21). An additional RCT, the RTOG 91-11 trial, comprising three treatment arms (induction chemotherapy + radiation (RT) vs. concurrent CRT vs. RT) indicated superior locoregional control and larynx preservation rate in the concurrent CRT treatment arm; however, no difference was observed in OS (22). The updated 10-year follow-up for the RTOG 91-11 study revealed that there was a trend toward a poorer survival in the concurrent CRT treatment arm, which may be attributed to the increased incidence of toxicity (24). 

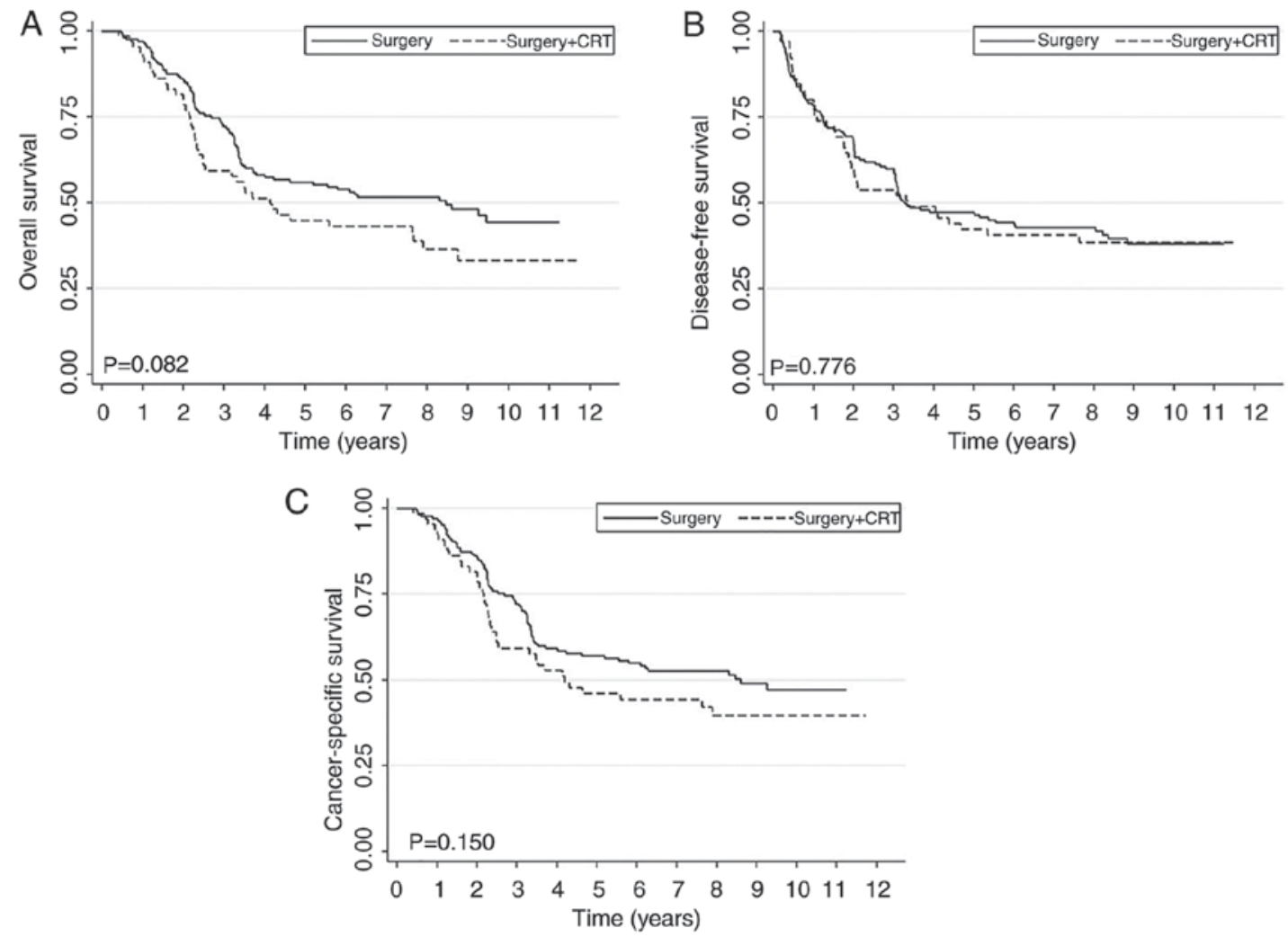

Figure 1. Survival analysis of treatment groups prior to PSM (A) Overall survival in the two treatment modality groups prior to PSM. (B) Disease-free survival in the two treatment modality groups prior to PSM. (C) Cancer-specific survival in the two treatment modality groups prior to PSM. There was no statistical significance between the two treatment groups prior to PSM. PSM, propensity score matching; CRT, adjuvant chemoradiotherapy.
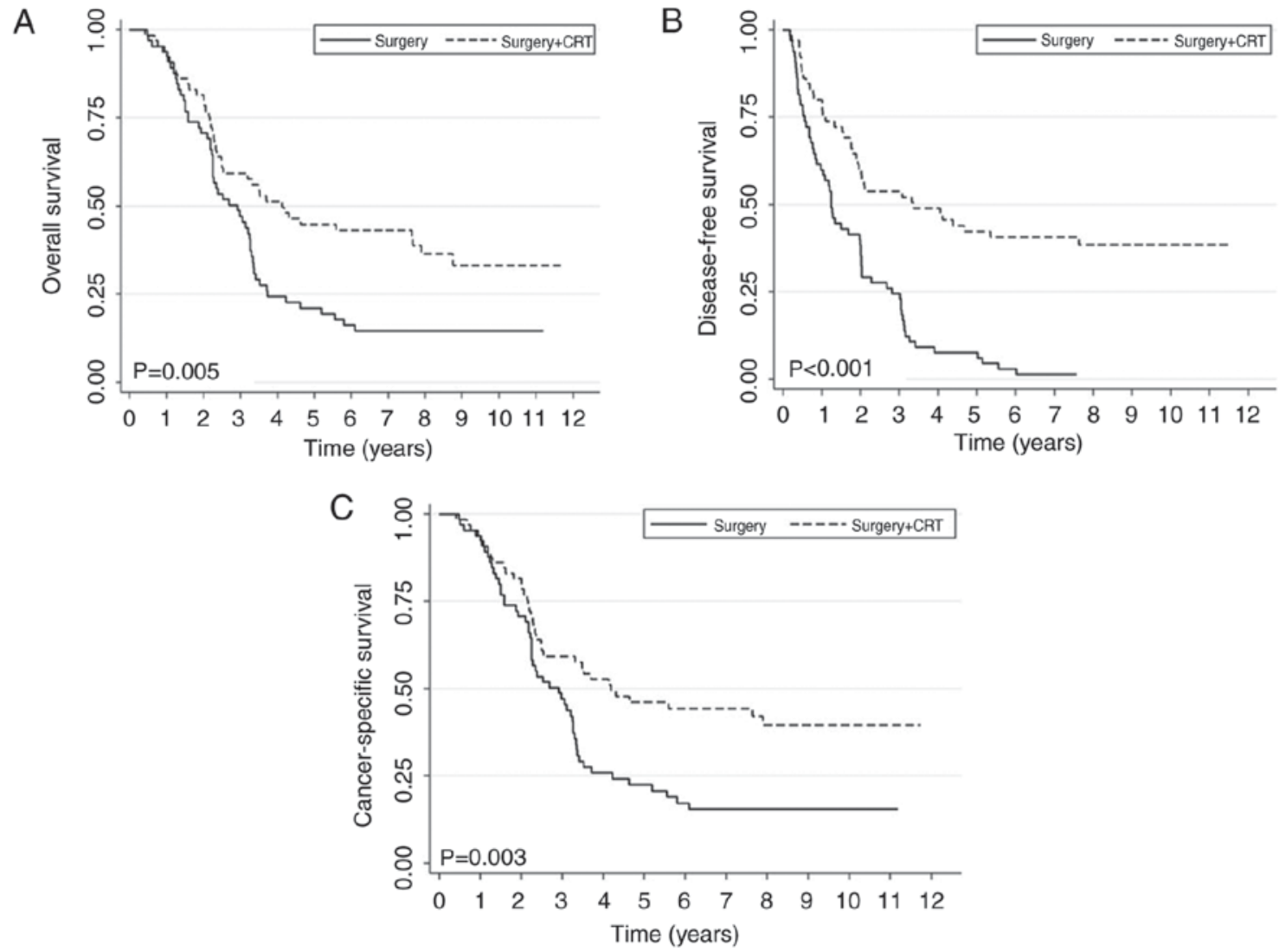

Figure 2. Survival analysis of treatment groups following PSM. (A) Overall survival in the two treatment modality groups following PSM. (B) Disease-free survival in the two treatment modality groups following PSM. (C) Cancer-specific survival in the two treatment modality groups following PSM. There was statistical significance between the two treatment groups following PSM. PSM, propensity score matching; CRT, adjuvant chemoradiotherapy. 

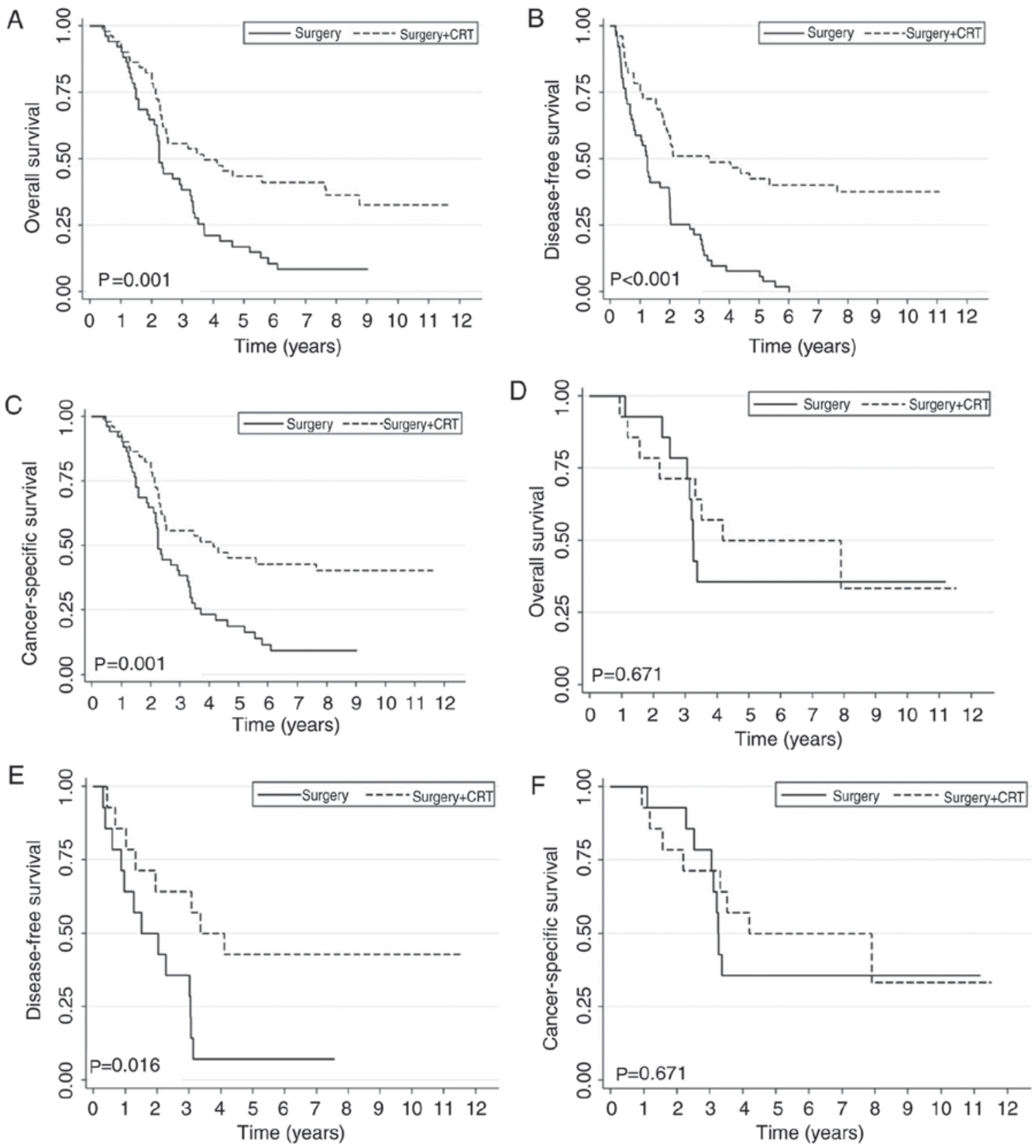

Figure 3. Patients with stage IV disease exhibit additional survival benefit in the surgery + CRT group. (A) Overall survival in the two treatment modality groups for patients with stage IV disease. (B) Disease-free survival in the two treatment modality groups for patients with stage IV disease. (C) Cancer-specific survival in the two treatment modality groups for patients with stage IV disease. (D) Overall survival in the two treatment modality groups for patients with stage III disease. (E) Disease-free survival in the two treatment modality groups for patients with stage III disease. (F) Cancer-specific survival in the two treatment modality groups for patients with stage III disease. CRT, adjuvant chemoradiotherapy.

There has been a decreased survival rate in laryngeal cancer in previous decades with the increased application of different treatment approaches (26). Hoffman et al (26) suggested that RT alone or CRT was correlated with an increased mortality rate compared with surgery in $\mathrm{T} 3$ glottic cancer. An RCT conducted in France including patients with T3 primary laryngeal tumors demonstrated significantly improved survival in the group undergoing immediate surgery compared with patients receiving induction chemotherapy followed by RT (25). Previous studies revealed that the 5-year OS and DFS rates in patients with advanced LC were 60.8-71.6 and $41.0-57.8 \%$, respectively, with regard to different treatment regimens $(23,27)$. The present study demonstrated that the 5-year OS and DFS rates were 55.2 and $47.4 \%$, respectively, which supported previously published data.

Studies have indicated that the lymph node status is one of the most significant prognostic factors in patients with LC $(28,29)$. Smoking and being of an elderly age are also risks factors in patients with $\mathrm{LC}$, but the effects of age in the prognosis of LC remain controversial (30-32). The multivariate analysis in the present study demonstrated that the patients' clinical stage and nodal status were independent indicators in survival outcome. Age was statistically significant in univariate analysis, but it was not an independent factor. Smoking was not a risk factor in the present study and requires verification with an increased number of study participants. 
A

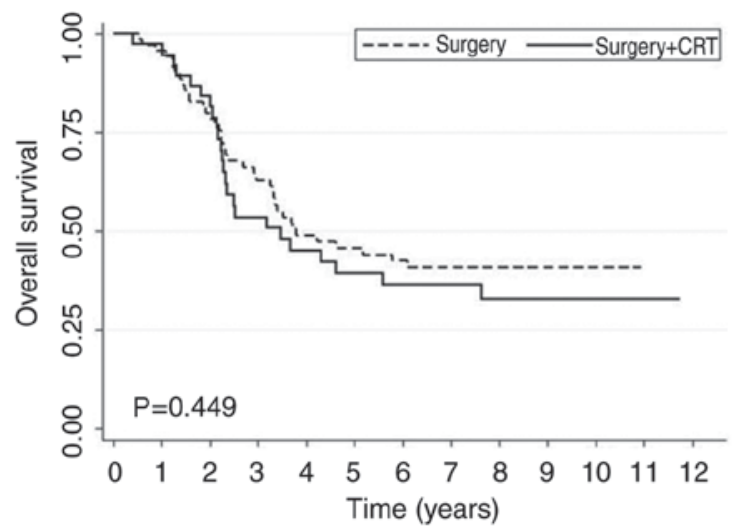

C



$E$

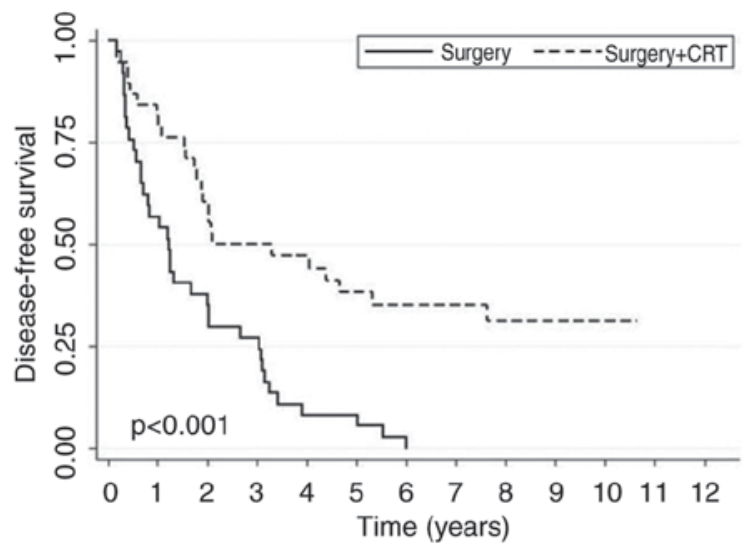

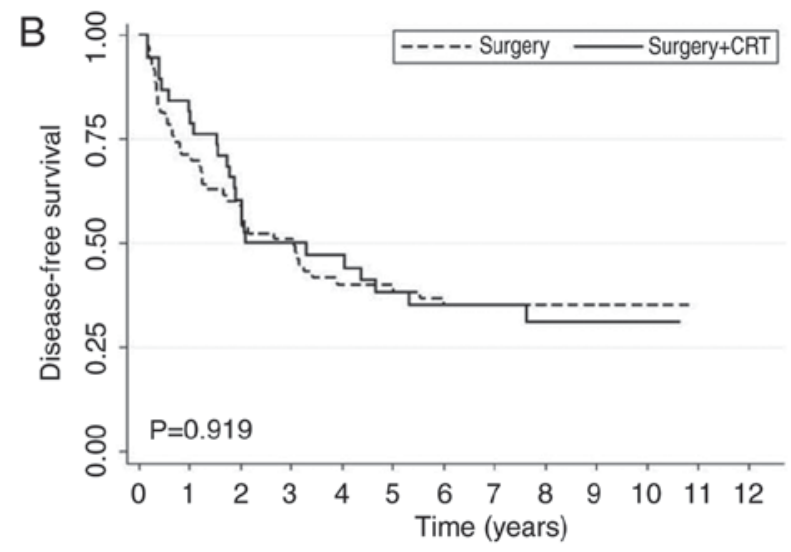
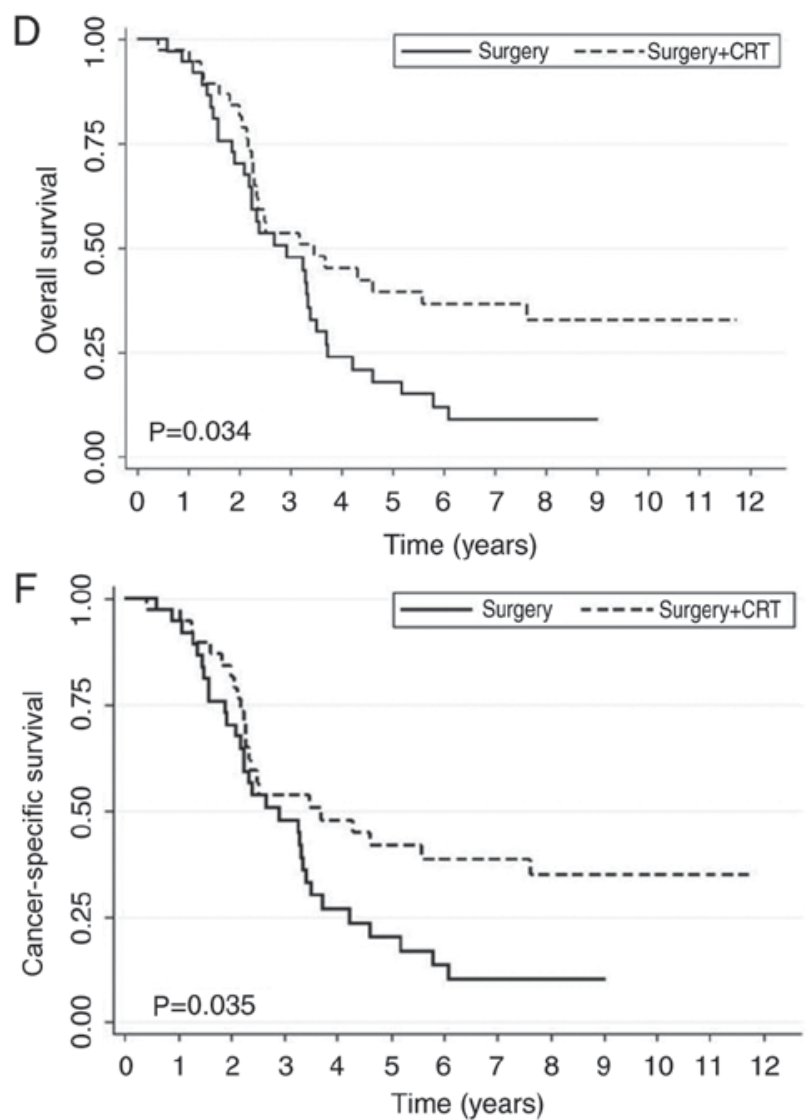

Figure 4. Patients with pN2 disease exhibit additional survival benefit in the surgery + CRT group following matching by T stage. (A) Overall survival in the two treatment modality groups for patients with $\mathrm{pN} 2$ disease prior to matching. (B) Disease-free survival in the two treatment modality groups for patients with pN2 disease prior to matching. (C) Cancer-specific survival in the two treatment modality groups for patients with pN2 disease prior to matching. (D) Overall survival in the two treatment modality groups for patients with pN2 disease subsequent to matching. (E) Disease-free survival in the two treatment modality groups for patients with $\mathrm{pN} 2$ disease subsequent to matching. (F) Cancer-specific survival in the two treatment modality groups for patients with pN2 disease subsequent to matching. CRT, adjuvant chemoradiotherapy.

Furthermore, there is a concern for the long-term toxicity and for the methods of selecting patients utilizing surgical or non-surgical treatments as the primary treatment strategies $(24,33)$. Treatment varies in different geographical locations as there is currently no optimal treatment in clinical practice (34). Certain studies have supported the hypothesis that postoperative RT does not provide additional survival effects in patients with LC, while other studies have suggested that patients receiving surgery with postoperative RT have improved survival $(32,35,36)$. Chen and Halpern (37) demonstrated almost equivalent efficacy for CRT and total laryngectomy for stage III disease, but significant differences in survival for all patients with advanced LC in a hospital-based study. Analysis of the National Cancer Data Base revealed that patients with stage III and IV disease treated with surgery as the primary treatment strategy had improved 5-year relative survival compared with those treated with irradiation (with or without chemotherapy) among 158,426 LC cases (26). A cross-section study using Surveillance, Epidemiology and End Results-Medicare data demonstrated that an improved survival benefit was observed following surgery with adjuvant RT of the whole LC cohort (36). However, there remains a paucity in the current literature of data to provide detailed descriptions of the comparison of the treatment modalities 
for advanced LSCC. In the present study, 232 patients with advanced LSCC were compared with 2 treatment modalities: Surgery vs. surgery + CRT. The results revealed that patients who underwent surgery + adjuvant CRT had improved survival outcomes compared with patients who were treated with surgery alone in the overall cohort. Subsequent stratification demonstrated that the clinical effect was limited in patients with pN2 disease and patients with stage IV disease. The inadequate patient number meant that whether patients with stage III LC would receive a survival benefit with adjuvant CRT could not be discerned. Additional studies will be required in the coming years to elucidate the causes of this apparent decrease in larynx cancer survival, and/or improve the selection of patients for surgical and non-surgical treatments.

Several limitations of the present study should be noted: In the subgroup analysis, with regard to the potential benefit from the adjuvant CRT in patients with or without positive surgical margins, the benefit of adjuvant CRT in the subgroup of patients with positive surgical margins was not determined, as all the patients with positive surgical margins were in the surgical + adjuvant CRT group. For the patients with pN2+ disease, no statistical significance was observed among the unmatched 232 patients. Following matching, an additional survival benefit was observed in the patients with LC receiving adjuvant CRT. In addition, as LSCC is a predominantly male disease, and because there were a limited number of females in the present study due to the relatively small sample size, the potential effects of sex were not assessed.

In conclusion, patients with stage IV LSCC may benefit from adjuvant CRT following initial total laryngectomy. It is worth noting that a significant limitation of the present study was its retrospective design. As it includes the data from only 1 institution, the results require validation by a prospective multicenter study.

\section{Acknowledgements}

The authors would like to thank Dr Jian Zhou and Dr Chiyao Hsueh (Eye, Ear, Nose and Throat Hospital of Fudan University, Shanghai, China) for their collection and follow-up of clinical cases. They would also like to thank Dr Patricia A. McEvoy-Jamil (The University of Texas School of Public Health) for her assistance and editing of the English language.

\section{Funding}

The present study was supported in part by Shen Kang Hospital Development of Shanghai Municipality (grant no. SHDC12015114), Science and Technology Commission of Shanghai Municipality (grant no. 16411950101), Shanghai Natural Science Foundation of China (grant no. 17ZR1404700) and Shanghai Pudong District Health Bureau of Health (IPPF) Technology Projects (grant no. PW2016D-11).

\section{Availability of data and materials}

The datasets used and analyzed during the current study are available from the corresponding author on reasonable request.

\section{Authors' contributions}

MZ and WD conceived the study and completed the manuscript. WD and XL analyzed and interpreted the patient data. HG, CL and YW reviewed, collected and analyzed data. LT and LZ designed the study acquired the data. LZ supervised the whole study, revised the manuscript and gave final approval of the version to be published. All the authors contributed to write the manuscript.

\section{Ethics approval and consent to participate}

All patients gave their full consent to participate in the present study, and a written consent form was obtained from each patient. The research protocol was approved by the Institutional Review Board of Eye, Ear, Nose and Throat Hospital of Fudan University.

\section{Patient consent for publication}

A written consent form was obtained from each patient.

\section{Competing interests}

The authors declare that they have no competing interests.

\section{References}

1. Eskiizmir G, Tanyeri Toker G, Celik O, Gunhan K, Tan A and Ellidokuz H: Predictive and prognostic factors for patients with locoregionally advanced laryngeal carcinoma treated with surgical multimodality protocol. Eur Arch Otorhinolaryngol 274: 1701-1711, 2017.

2. Steuer CE, El-Deiry M, Parks JR, Higgins KA and Saba NF: An update on larynx cancer. CA Cancer J Clin 67: 31-50, 2017.

3. Siegel RL, Miller KD and Jemal A: Cancer statistics, 2017. CA Cancer J Clin 67: 7-30, 2017.

4. Du L, Li H, Zhu C, Zheng R, Zhang S and Chen W: Incidence and mortality of laryngeal cancer in China, 2011. Chin J Cancer Res 27: 52-58, 2015.

5. Skora T, Nowak-Sadzikowska J, Mucha-Malecka A, Szyszka-Charewicz B, Jakubowicz J and Glinski B: Postoperative irradiation in patients with pT3-4N0 laryngeal cancer: Results and prognostic factors. Eur Arch Otorhinolaryngol 272: 673-679, 2015.

6. Trifiletti DM, Smith A, Mitra N, Grover S, Lukens JN, Cohen RB, Read P, Mendenhall WM, Lin A and Swisher-McClure S: Beyond positive margins and extracapsular extension: Evaluating the utilization and clinical impact of postoperative chemoradiotherapy in resected locally advanced head and neck cancer. J Clin Oncol 35: 1550-1560, 2017.

7. Cooper JS, Pajak TF, Forastiere AA, Jacobs J, Campbell BH, Saxman SB, Kish JA, Kim HE, Cmelak AJ, Rotman M, et al: Postoperative concurrent radiotherapy and chemotherapy for high-risk squamous-cell carcinoma of the head and neck. N Engl J Med 350: 1937-1944, 2004.

8. Bernier J, Cooper JS, Pajak TF, van Glabbeke M, Bourhis J, Forastiere A, Ozsahin EM, Jacobs JR, Jassem J, Ang KK and Lefèbvre JL: Defining risk levels in locally advanced head and neck cancers: A comparative analysis of concurrent postoperative radiation plus chemotherapy trials of the EORTC (\#22931) and RTOG (\#9501). Head Neck 27: 843-850, 2005.

9. Davis GE, Schwartz SR, Veenstra DL and Yueh B: Cost comparison of surgery vs. organ preservation for laryngeal cancer. Arch Otolaryngol Head Neck Surg 131: 21-26, 2005.

10. Shah JP, Karnell LH, Hoffman HT, Ariyan S, Brown GS, Fee WE, Glass AG, Goepfert H, Ossoff RH and Fremgen A: Patterns of care for cancer of the larynx in the United States. Arch Otolaryngol Head Neck Surg 123: 475-483, 1997.

11. Karatzanis AD, Psychogios G, Waldfahrer F, Kapsreiter M,Zenk J, Velegrakis GA and Iro H: Management of locally advanced laryngeal cancer. J Otolaryngol Head Neck Surg 43: 4, 2014. 
12. De Felice F, Blanchard P, Levy A, Nguyen F, Gorphe P, Janot F, Temam $S$ and Tao Y: Treatment of squamous cell carcinoma of the posterior pharyngeal wall: Radiotherapy versus surgery. Head Neck 1 (Suppl 38): E1722-E1729, 2016.

13. Edge SB, Byrd DR, Compton CC, Fritz AG, Greene FL, Trotti A, editors: American joint committee on cancer. AJCC cancer staging manual. 7th ed. New York, NY: Springer, 2010.

14. Austin PC: Optimal caliper widths for propensity-score matching when estimating differences in means and differences in proportions in observational studies. Pharm Stat 10: 150-161, 2011.

15. Austin PC: An introduction to propensity score methods for reducing the effects of confounding in observational studies. Multivariate Behav Res 46: 399-424, 2011.

16. Vlachtsis K, Nikolaou A, Markou K, Fountzilas G and Daniilidis I: Clinical and molecular prognostic factors in operable laryngeal cancer. Eur Arch Otorhinolaryngol 262: 890-898, 2005.

17. Byrd SA, Xu MJ, Cass LM, Wehrmann DJ, Naunheim M, Christopher K, Dombrowski JJ, Walker RJ, Wirth L, Clark J, et al: Oncologic and functional outcomes of pretreatment tracheotomy in advanced laryngeal squamous cell carcinoma: A multi-institutional analysis. Oral Oncol 78: 171-176, 2018.

18. Fu X, Zhou Q and Zhang X: Efficacy comparison between total laryngectomy and nonsurgical organ-preservation modalities in treatment of advanced stage laryngeal cancer: A meta-analysis. Medicine (Baltimore) 95: e3142, 2016.

19. Sheahan P: Management of advanced laryngeal cancer. Rambam Maimonides Med J 5: e0015, 2014.

20. O'Neill CB, O'Neill JP, Atoria CL, Baxi SS, Henman MC Ganly I and Elkin EB: Treatment complications and survival in advanced laryngeal cancer: A population-based analysis. Laryngoscope 124: 2707-2713, 2014.

21. Department of Veterans Affairs Laryngeal Cancer Study Group; Wolf GT, Fisher SG, Hong WK, Hillman R, Spaulding M, Laramore GE, Endicott JW, McClatchey K and Henderson WG: Induction chemotherapy plus radiation compared with surgery plus radiation in patients with advanced laryngeal cancer. $N$ Eng J Med 324: 1685-1690, 1991.

22. Forastiere AA, Goepfert H, Maor M, Pajak TF, Weber R, Morrison W, Glisson B, Trotti A, Ridge JA, Chao C, et al: Concurrent chemotherapy and radiotherapy for organ preservation in advanced laryngeal cancer. N Engl J Med 349: 2091-2098, 2003.

23. Luo XN, Chen LS, Zhang SY, Lu ZM and Huang Y: Effectiveness of chemotherapy and radiotherapy for laryngeal preservation in advanced laryngeal cancer: A meta-analysis and systematic review. Radiol Med 120: 1153-1169, 2015.

24. Forastiere AA, Zhang Q, Weber RS, Maor MH, Goepfert H Pajak TF, Morrison W, Glisson B, Trotti A, Ridge JA, et al: Long-term results of RTOG 91-11: A comparison of three nonsurgical treatment strategies to preserve the larynx in patients with locally advanced larynx cancer. J Clin Oncol 31: 845-852, 2013.
25. Richard JM, Sancho-Garnier H, Pessey JJ, Luboinski B, Lefebvre JL, Dehesdin D, Stromboni-Luboinski M and Hill C: Randomized trial of induction chemotherapy in larynx carcinoma. Oral Oncol 34: 224-228, 1998.

26. Hoffman HT, Porter K, Karnell LH, Cooper JS, Weber RS, Langer CJ, Ang KK, Gay G, Stewart A and Robinson RA: Laryngeal cancer in the United States: Changes in demographics, patterns of care, and survival. Laryngoscope 116 (Suppl 111): $1-13,2006$

27. Gourin CG, Conger BT, Sheils WC, Bilodeau PA, Coleman TA and Porubsky ES: The effect of treatment on survival in patients with advanced laryngeal carcinoma. Laryngoscope 119: 1312-1317, 2009

28. Gonzalez-Marquez R, Rodrigo JP and Suarez Nieto C: Prognostic significance of postoperative wound infections after total laryngectomy. Head Neck 34: 1023-1027, 2012.

29. Jose J, Coatesworth AP, Johnston C and MacLennan K: Cervical node metastases in squamous cell carcinoma of the upper aerodigestive tract: The significance of extracapsular spread and soft tissue deposits. Head Neck 25: 451-456, 2003.

30. Lubin JH, Gaudet MM, Olshan AF, Kelsey K, Boffetta P, Brennan $\mathrm{P}$, Castellsague $\mathrm{X}$, Chen $\mathrm{C}$, Curado MP, Dal Maso L, et al: Body mass index, cigarette smoking, and alcohol consumption and cancers of the oral cavity, pharynx, and larynx: Modeling odds ratios in pooled case-control data. Am J Epidemiol 171: 1250-1261, 2010.

31. Ramroth H, Schoeps A, Rudolph E, Dyckhoff G, Plinkert P, Lippert B, Feist K, Delank KW, Scheuermann K, Baier G, et al: Factors predicting survival after diagnosis of laryngeal cancer. Oral Oncol 47: 1154-1158, 2011.

32. Zhang SY, Lu ZM, Luo XN, Chen LS, Ge PJ, Song XH, Chen SH and Wu YL: Retrospective analysis of prognostic factors in 205 patients with laryngeal squamous cell carcinoma who underwent surgical treatment. PLoS One 8: e60157, 2013.

33. Megwalu UC and Sikora AG: Survival outcomes in advanced laryngeal cancer. JAMA Otolaryngol Head Neck Surg 140: 855-860, 2014.

34. Corry J, Peters L, Kleid S and Rischin D: Larynx preservation for patients with locally advanced laryngeal cancer. J Clin Oncol 31: 840-844, 2013

35. Papadas TA, Alexopoulos EC, Mallis A, Jelastopulu E, Mastronikolis NS and Goumas P: Survival after laryngectomy: A review of 133 patients with laryngeal carcinoma. Eur Arch Otorhinolaryngol 267: 1095-1101, 2010

36. Gourin CG, Dy SM, Herbert RJ, Blackford AL, Quon H, Forastiere AA, Eisele DW and Frick KD: Treatment, survival, and costs of laryngeal cancer care in the elderly. Laryngoscope 124: 1827-1835, 2014

37. Chen AY and Halpern M: Factors predictive of survival in advanced laryngeal cancer. Arch Otolaryngol Head Neck Surg 133: 1270-1276, 2007. 